\title{
Beyond Fellowship: How to Identify the Right Job for You
}

\author{
Nicolas Pulham ${ }^{1} \cdot$ Paul Feuerstadt ${ }^{2,3}$
}

Published online: 18 January 2016

(c) Springer Science+Business Media New York 2016

\begin{abstract}
"What are your plans after graduation?" This question can often be overheard between graduating fellows and their mentors. This seemingly innocent inquiry can be anxietyprovoking for fellows as they enter their final year of training. The path of medical training is standardized with universal applications and accessible information regarding medical schools, residencies, and fellowships. As the final phase of training begins, it can feel as though this welltrodden path has led to uncharted territory. The fellowship curriculum prepares trainees to handle clinical management of disease and critical thought, but does not usually provide the same degree of guidance regarding career development. Thus, this guide was developed to provide an action plan for you, the graduating fellow and job applicant, to follow as you begin the process of finding your ideal job.

Preparing a professional curriculum vitae (CV) that effectively markets you is one of the first steps for the job seeker. The process of updating the $\mathrm{CV}$ with achievements and experiences obtained during fellowship helps you to focus on your strengths, skills, and desired directions for your future. For this reason, your CV, which is ideally prepared in the beginning of the final year of fellowship, should focus on the type of position of interest so as to be able to capture the attention of potential employers. For
\end{abstract}

Paul Feuerstadt

pfeuerstadt@gastrocenter.org

1 Division of Gastroenterology, Yale University School of Medicine, New Haven, CT, USA

2 Gastroenterology Center of Connecticut, Yale University School of Medicine, New Haven, CT, USA

32200 Whitney Avenue, Suite 200, Hamden, CT 06880, USA example, those applying for an academic clinical educator position should highlight teaching experiences, awards, and lecturing opportunities. Potential employers should be able to readily identify any clinical niche or special skill acquired during fellowship training in your CV. Upon its completion, it is wise to have your CV reviewed by mentors and others prior to its distribution to potential employers.

The next step is to set career goals. Do you want to care for patients as a primary responsibility? Are you looking for leadership or managerial positions? Will research and publishing be a primary focus? The position that you target should offer a pathway to fulfill those goals. There are numerous career tracks within academia ranging from a primary focus on clinical or basic science research to clinical duties and education. Overlap positions that contain both teaching and research responsibilities also exist. Alternatively, private practice can offer a variety of options including different structures (e.g., solo practice, single specialty practice, multispecialty practice, and hospital employed) and philosophies (e.g., independent practices, "hybrid practices" that have an academic affiliation and teaching responsibilities). For the graduating fellow who has developed an affinity for academic endeavors such as research, publishing manuscripts, teaching, and lecturing, a career within academia is the obvious choice. For the remainder, finding a position that aligns with their goals might involve keeping an open mind about both academia and private practice.

For many, geographic location is one of the most important considerations for future employment. The geographic transiency of the training period contrasts with the stability of practice and establishing "roots" in one area. Thus, choosing a geographic region for a job requires the consideration of multiple factors such as an urban 
versus a rural environment, spousal employment, climate, extended family location, and activities or amenities of an area. In addition to these factors, densely populated areas are sometimes more desirable, but can be saturated with similar specialists which increases the challenge of finding a good position. Rural and underserved areas may offer financial incentives and have better availability. By weighing these factors, you can focus your search and start to explore positions available in a desired location.

The process of identifying available positions is the next phase of the job search. This can be a daunting task as there is no standard process available to find these opportunities. The best initial step is to contact recently graduated fellows who can usually provide an insightful and accurate view of their experience, including which resources they found most helpful. Next, you should speak with mentors and instructors from your current and previous institutions, who, due to their training of scores of trainees, are unusually resourceful and helpful, providing ideas and insights that will help further focus your goals and career path. Even if a private practice position is being sought, it is still wise to discuss your job search with an academician. They might be aware of job opportunities or be able to connect you with someone relevant to the location or job-specific track of interest. If interested in private practice, speaking with practitioners who have chosen that career path can also be helpful. The process of mentor referral, which usually includes a telephone call on your behalf, is mutually beneficial for the applicant and for the position. Through this process, the trusted physician validates your candidacy to the group or division.

Once the process of obtaining references from colleagues and mentors has been exhausted, one should explore other options for identifying opportunities. Advertisements in medical journals (e.g., Gastroenterology, American Journal of Gastroenterology, New England Journal of Medicine), job boards at national meetings (e.g., Digestive Disease Week or the American College of Gastroenterology Annual Meeting), and physician recruiters are resources available to fellows. One additional strategy is to perform a search for all academic divisions and practices within your desired geographic region. Once this list has been generated, you should begin the process of "cold-calling" to ask whether a position is available. It is important to realize that sometimes the ideal and most sought-after jobs are not advertised. Although "cold-calling" may be a challenging way to discover opportunities, it will offer you the peace-of-mind that all avenues have been explored.
The next phase of securing the ideal job is through interviews and job offer analysis. Typically you will interact with potential employers through a series of interviews and social interactions. A job offer commonly consists of either an offer sheet outlining relevant details of the position (e.g., salary, benefits, call) or a formal contract. Although an applicant's tendency will be to immediately focus on the base salary offer, it is essential to consider the entire package being presented (Fig. 1). This holds true for positions in academia and in private practice. Salary should not be the only consideration; one should consider the call schedule (e.g., more frequent "light" call versus less frequent "heavy" call), culture of the division (e.g., work-life balance, camaraderie among the clinicians and the staff), the age distribution of the clinicians (e.g., many clinicians with school-age children will likely need the same weeks off each year, retiring clinicians could potentially decrease their contribution to the call schedule), and the community reputation of the group or division. For private practice, one should additionally consider opportunities for partnership (e.g., timing and structure of buy-in), ownership of ancillary services (e.g., endoscopy center, research center, pathology laboratory, infusion center), and the composition of the practice administration. Academic considerations should include whether the offer includes protected time for research, expected annual number of publications, number of weeks of coverage of the inpatient service, expected participation in hospital committees, and available resources for academic pursuits (e.g., research coordinators, statisticians).

The final phase in the decision process involves performing due diligence on the opportunity. This might include performing internet searches in order to ascertain the practice's community reputation, speaking with endoscopy nurses, reaching out to hospital administrators, and inquiring about the last few clinicians that have left the position. The group or division should provide the contact information for these former colleagues in order to enable you to independently converse with them regarding their rationale for leaving. Although clinicians usually leave a practice for personal or family reasons, they sometimes leave due to the nature of the practice itself, essential information for you to gain prior to signing the contract. Each of these resources will provide you with a wellrounded view of the opportunity. Once you have decided to focus on one position, it is prudent to have a lawyer who is experienced with medical contracts review the contract.

There is no perfect method for finding a job. By considering the ideas and concepts presented, we hope you, the job applicant, will be able to identify your goals, the job 
Fig. 1 Financial considerations of a job offer

\section{Consider the Entire Job Offer}

\section{Job 1}

Base Salary: $\$ 300,000$

No Signing Bonus

No Moving Allowance

No Malpractice Insurance

No Health Insurance Coverage

No Retirement Contribution

No Societal Dues

No CME allowance

\section{Job 2}

\section{Base Salary: $\$ \mathbf{2 7 5 , 0 0 0}$}

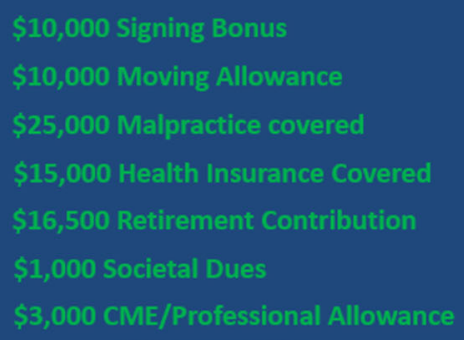

$\$ 10,000$ Signing Bonus

$\$ 10,000$ Moving Allowance

$\$ 25,000$ Malpractice covered

$\$ 15,000$ Health Insurance Covered

$\$ 16,500$ Retirement Contribution

$\$ 3,000 \mathrm{CME} /$ Professional Allowance
$\$ 300,000$ per year with no bonus originally
$\$ 335,500$ per year plus $\$ 20,000$ bonus originally options available to meet those aspirations, many factors affecting your job choice, and find the best fit for your career. A methodical approach will assuredly convert the fears of the question "What's after fellowship?" to confidence and excitement for your path to finding an ideal position.

\section{Compliance with ethical standards}

Conflict of interest There was no conflict of interest to declare for either author. 